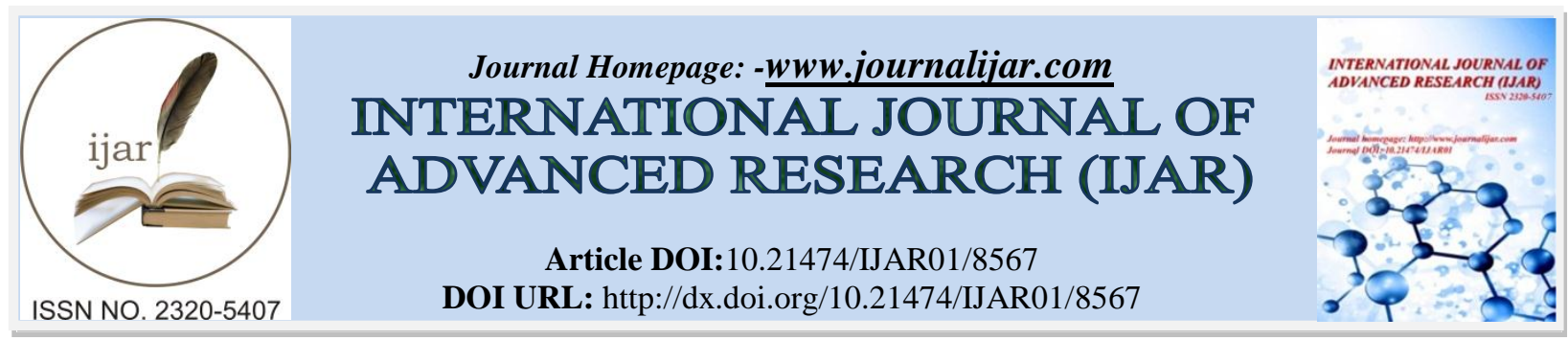

RESEARCH ARTICLE

\title{
COMPARISON OF DYNAMIC BALANCE IN MALE FOOTBALL AND BASKETBALL PLAYERS USING MODIFIED BASS TEST.
}

\author{
Paryushi V. Rami ${ }^{1}$ and M. M. Prabhakar ${ }^{2}$. \\ 1. Senior Lecturer, JG College Of Physiotherapy, Ahmedabad, Gujarat. \\ 2. Medical Superintendent, Civil Hospital, Ahmedabad, Gujarat.
}

\section{Manuscript Info}

Manuscript History

Received: 14 December 2018

Final Accepted: 16 January 2019

Published: February 2019

Key words:-

Dynamic balance, Modified Bass Test, Football, Basketball.

\begin{abstract}
Background: Dynamic balance is basal ability which desirable in sports that require stability particularly during moving and quickly reacting to changing circumstances. Poor dynamic balance previously has been related with sports injuries. Dynamic balance required while performing tasks in competitive sports like football and basketball. Thus, the purpose of this study is to compare dynamic balance by using modified bass test in male football and basketball players.

Method: The study conducted on 50 male players, football $(n=25)$ and basketball $(n=25)$ from sports Academy of Ahmedabad, Gujarat. They were selected for the study with purposive sampling. Dynamic balance was assessed by using Modified Bass Test.

Result: Independent $\mathrm{t}$ test performed to find the significant difference between football and basketball players. There was significant difference found in dynamic balance by using Modified Bass test between football and basketball players. $(\mathrm{p}<0.01)$

Conclusion: Football player displayed higher dynamic balance than Basketball players.

Copy Right, IJAR, 2019,. All rights reserved.
\end{abstract}

\section{Introduction:-}

Balance is system of maintaining the body center of gravity over its base of support with minimal sway (Horak, 1987; Shumway-Cook\&Woollacott, 1995). Balance involve synchronization of many muscles of the body and incorporation of sensory information (Çelenk et al.,2018). Balance require integration of visual, vestibular, and somatosensory system to accomplish smooth and coordinated neuromuscular action. (Jacobson et al., 1997; Nashner, 1982). Balance is classified into static and dynamic, which is important to excelling in sports.For maintaining static and dynamic balance, it required exceptionally compound of neuromuscular mechanism(Gerbino et al., 2007; Michael \&Rogers, 2003).Dynamic balance refers to body's ability to retain poise or steadiness when moving or shifting from one situation to another (Khasawneh, 2015). Dynamic balance has an important role in most daily activity and crucial element for execution of sports skill like sudden changes in motion and improving sports performance.For Athletic motor skill development essential component is dynamic balance (Elena et al., 2015). Dynamic Balance is fundamental component of many sports like Football and Basketball. Each sport has different balance requirements and demands on the players according to their physical task and environmental conditions (Hrysomallis, 2011).Dynamic Balance is profound in sports player as they are frequently exposed to the situations where balance is dynamically challenged (Hrysomallis et al., 2006).For example, Football player frequently perform passing, dribbling and shooting skills with lower extremity while wearing studded or simple football boots on

Corresponding Author:-Paryushi V. Rami.

Address:-Senior Lecturer, JG College Of Physiotherapy, Ahmedabad, Gujarat. 
variable turf conditions (Bresselet al., 2007; Orchard, 2002). Basketball players habitually involve where balance instability occur such as changes in directions, penetration in to defensive perimeter and dribbling while they wear shoes on flat and rough surface (Melamet al., 2016; Boccoliniet al., 2013). Balance dysfunction has been identified as injury risk in sport. Poor Dynamic balance has been associated with decreased neuromuscular control which leads to increase postural sway(Elena et al., Paul et al., 2015; Paternoet al., 2004). Brown CN et al. reported that chronic ankle stability is interconnected with static and dynamic deficit. (Brown et al., 2007). "High Risk" team sports like basketball, handball, football and volleyball arise with ankle sprain which comprises between 15-75\% of all sportrelated injuries (Fernandez et al., 2007). The most common injuries involve the lower extremities especially ankle sprain which often result during sports specific activities like jumping, landing sprinting and quick and unexpected changes in direction where dynamic stability altered (Fong et al., 2007).In basketball and football players, it was found that lower extremity injury risk is significantly related with poor dynamic balance ability (Robert et al., 2013;Plisky et al., 2006). Instability during the dynamic task in sports not only disrupts expected performance of every branch of sports but also cause injuries (Gürkan, 2016). Dynamic balance is crucial for motor skill based tasks in sports as well as for injury prevention.There are various number of reliable methods to test dynamic balance. Modified Bass Test is one of that test which measure jump ability and maintain balance during movement and after movement(Barry et al., 1988). Evaluation of Dynamic balance is necessary in players to define and change training programs, rate of progression in balance score and also help to analyse the effectiveness of neuromuscular efficiency. Thus, the purpose of the study is to compare dynamic balance in male football and basketball players using Modified Bass Test. So, the study hypothesized that dynamic balance will be different between male football and basketball player by using Modified Bass Test.

\section{Materials and Methods:-}

This study was cross-sectional study design. Fifty male players (25 Football players and 25 Basketball players) participated from different sports Academy of Ahmedabad, Gujarat. The included subjects were male players with age 13-16 years. Subjects included were currently competing in only one sport for previous one year and not be involved in a balance training program outside of their typical sport training. Subjects were excluded with the current history of hip, knee and ankle surgery, visual problem, vestibular problem, history of concussion 12 weeks before study, history of lower extremity injury in last 6 months. The study was approved by Institutional ethical committee. All subjects signed written informed consent before testing.

\section{Procedure:-}

The Modified Bass Test of Dynamic Balance was used to measure dynamic Balance. This test has a reliability of .75 (Barry et al., 1988). Eleven $2.5 \mathrm{~cm} \times 2 \mathrm{~cm}$ pieces of marking tape were cut and tape in the pattern shown in figure 1 . Beginning at a line marked "start" with right footed with one-leg stance. Subject leaped to the first tape mark (\#1) with left foot and tried to hold a steady position on the ball of his left foot for as many seconds as possible up to a maximum of 5 seconds. Subject then leaped to the second tape mark (\#2) with the right foot and so on, alternating the feet from tape mark to tape mark. The subject remained on each tape mark for as many seconds as possible up to a maximum of 5 seconds. The foot of subject completely covered the tape so that the tape was not seen. The subject scored 5 points for each successful landing on tape mark. In addition, 1 point was awarded for each second the balance was held up to 5 seconds per mark. Thus, the subject was able to earn a maximum of 10 points per marker or a total of 100 points for the entire test, with a higher score indicating better balance.

The penalties for this test were classified in to landing errors and balance errors as follows:-

\section{Landing Errors:-}

The subject lost 5 points for improper landing if any of the following errors were committed: failing to stop upon landing from the leap, touching the heel or any other part of the body to the floor other than the ball of the supporting foot upon landing, or failing to completely cover the tape mark with the ball of the foot. Subject was allowed to reposition the body for the 5 second balance on the ball of the foot after making a landing error.

\section{Balance Errors:-}

The subject lost 1 point per second if either of the balance errors were committed before the completion of the 5 seconds: touching any part of the body to the floor other than the ball of the supporting foot, or moving the foot while in balance position. If the subjects lost balance, they had to step back on the proper marker and then leap to the next marker (Barry L, 1988; Ambegaonkar et al., 2011,2013). 


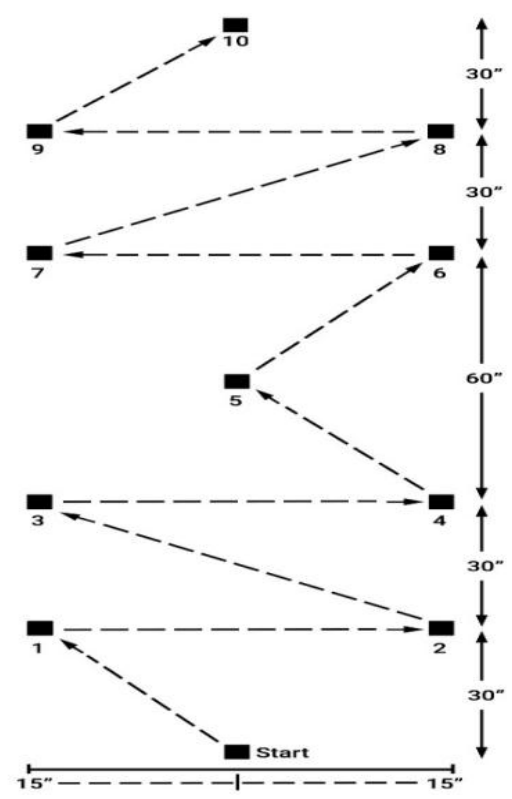

Figure 1:-floor pattern of modified bass dynamic balance test statistical analysis

In statistical evaluation of data SPSS (Statistical Package for the social sciences) version 20 was used and result were shown as mean and standard deviation. Normality distribution of data was determined by using Shapiro-Wilk Test. Independent t-test is used to find out the significant difference between groups. The level of significance was set as $\mathrm{p}<0.05$.

\section{Results:-}

The Demographic characteristics are shown in Table 1. It was seen that the mean age, weight, height, body mass index were $14.36 \pm 1.11$ years, $52.84 \pm 9.57 \mathrm{Kg}, \quad 1.65 \pm 0.10$ meters, $19.14 \pm 2.03 \mathrm{~kg} / \mathrm{m}^{2}$ for Football players; $14.40 \pm 1.12$ years, $57.44 \pm 9.58 \mathrm{Kg}, 1.67 \pm 0.07$ meters, $20.41 \pm 2.27 \mathrm{Kg} / \mathrm{m}^{2}$ for Basketball players. In table 2 , the result of Independent t-testshowed that statistically significant difference in Modified Bass Test between the dynamic balance value of football players (75.24 \pm 3.59$)$ and Basketball players $(63.76 \pm 2.95) \mathrm{p}(<0.01)$. Thus, Football players demonstrated higher dynamic balance than basketball players.

Table 1:-Demographic characteristics of subjects.

\begin{tabular}{|l|l|l|l|l|l|}
\hline Grops & $\begin{array}{l}\text { Number of } \\
\text { Sujects }\end{array}$ & $\begin{array}{l}\text { Age } \\
\text { Mean } \pm \text { SD } \\
\text { (years) }\end{array}$ & $\begin{array}{l}\text { Weight } \\
\text { Mean } \pm \text { SD } \\
(\mathrm{Kg})\end{array}$ & $\begin{array}{l}\text { Height } \\
\text { Mean } \pm \text { SD } \\
(\text { meters })\end{array}$ & $\begin{array}{l}\text { Body Mass Index } \\
\text { Mean } \pm S D \\
\left(\mathrm{Kg} / \mathrm{m}^{2}\right)\end{array}$ \\
\hline Football & 25 & $14.36 \pm 1.11$ & $52.84 \pm 9.57$ & $1.65 \pm 0.10$ & $19.14 \pm 2.03$ \\
\hline Basketball & 25 & $14.40 \pm 1.12$ & $57.44 \pm 9.58$ & $1.67 \pm 0.07$ & $20.41 \pm 2.27$ \\
\hline
\end{tabular}

Table 2:-Comparison of Modified Bass Test of Dynamic Balance between football and Basketball players

\begin{tabular}{|l|l|l|l|l|}
\hline Variable & $\begin{array}{l}\text { Football } \\
(\text { Mean } \pm \text { SD })\end{array}$ & $\begin{array}{l}\text { Basketball } \\
(\text { Mean } \pm \text { SD })\end{array}$ & t value & value \\
\hline $\begin{array}{l}\text { Modified Bass Test of } \\
\text { Dynamic Balance }\end{array}$ & $75.24 \pm 3.59$ & $63.76 \pm 2.95$ & 12.37 & $<0.01$ \\
\hline
\end{tabular}

\section{Discussion:-}

There were very few researches who had examined difference in dynamic balance ability among various players. This study compared dynamic balance in male football and basketball players using Modified Bass Test. Results of this study suggested that there was a significant difference in dynamic balance in male football and basketball player 
using Modified Bass Test $(\mathrm{p}<0.01)$. Modified Bass Test reveals that dynamic balance of football $(75.24 \pm 3.59)$ was higher than Basketball players (63.76 \pm 2.95$)$. The result may be due to football players frequently perform single-leg reaching movements outside their base of support during passing, shooting and receiving.Likewise, Modified Bass Test also require player to maintain balance on a single foot on a specific mark for predetermined amount of time and then reaching to next tape mark which challenges an individual's dynamic balance ability (Ambegaonkar et al., 2013). Modal et al. compared dynamic balance between volleyball and basketball players. They found that dynamic balance by Modified Bass test for volleyball player was higher than Basketball players which due to more involvement in more labour intensive activity of volleyball players than Basketball players(Mondal et al., 2016). Although Ghosh et al. compared dynamic balance among football, volleyball and hockey players and the result of study showed there was no significant difference in three different games. They suggested that may be all three games played nearly with high intensity required quicker change of position and direction. So, all three games are purely similar in nature from the stand point of speed and movement pattern(Ghosh\&Majumde, 2012).

According to Bressel et al. balance difference observed among sports might be because of distinctive sensorimotor challenges enforced by each sport. They explained this reason as they found in their study that of basketball players displayed inferior dynamic balance compared with soccer player (Bressel et al., 2007). This could be also rationale for current study for difference found between male football and Basketball players.

As per literature athletes have exhibited with superior balance ability compared to non athletes that suggesting balance enhanced by sports participation (Bressel et al., 2007; Matsuda et al.,2008). Ashutoshpandey et al. compared dynamic balance using SEBT between athletes and non-athletes. Result of their study showed better dynamic balance on dominant leg in athletes than non-athletes and the reason for obtaining superior balance in trained athletes they described mainly it depends on the nature of repetitive training experience which eventually influence the motor responses and individuals ability to attend proprioceptive and visual cues (Pandey \&Venugopal, 2016). Jennifer et al.found female collegiate soccer had greater dynamic balance than nonsoccer participants which reflect due to difference in training status (Thorpe\&Ebersole, 2008).

Football is a running game where player often undergo for intensive circumstances such as shooting, slippery grass, changing direction at different speed while running with ball to avoid being intersect by opposition which required high level dynamic balance(Gualtieri et al., 2008; Khuman et al., 2014). In sports, balance is essential component of common motor skill. Even the basketball players also require versatile control of balance to perform tasks like inbound possessing, passing, dribbling. For skilfully performance in basketball players they need unilateral and bilateral stability during controlling their center of mass while swaying in all directions (Marchetti et al., 2012).

According to results of this study basketball player showed inferior dynamic balance when compared to football, indicating the need for further balance training to basketball players. Balance training is effective for reduction of sports injuries and also for postural and neuromuscular improvements. Enhancement of balance can influence stability that eventually improve functional and sports performance. Balance assessment can be helpful to rate of improvement in balance score over time, for prescribe balance exercises to prevent injuries and improve performance.

Few limitation of current study should be recognized. This study is limited as we only assessed male players and future research can be performed on female players and also in different sports with also using the more different techniques of measurement of dynamic balance.

\section{Conclusion:-}

Based on finding of this study may be concludedthere is significant difference in dynamic balance between male football and basketball players using Modified Bass Test. The football player displayed higher dynamic balance compared with basketball players.

\section{Acknowledgements:-}

The authors extend their appreciation to football and basketball players and also thankful to player's trainer for generous support during our research work. 


\section{References:-}

1. Ambegaonkar, J., Caswell, S.V., Winchester, J.B., Shimokochi, Y., Cortes, N., Caswell A.M. (2013): Balance comparisons between female dancers and active nondancers. Res Q Exerc Sport., 84(1): 24-29.

2. Ambegaonkar, J., Redmond, C.J., Winter, C., Ambegaonka, S., Thompson, B. and Guyer, S. (2011): Ankle stabilizers affect agility but not vertical jump or dynamic balance performance. Foot Ankle Spec., 4(6): 354360.

3. Barry, L., Johnson, J. and Nelson, K. (1988): Practical Measurements for Evaluation in Physical Education. New Delhi: Surjeet Publication.

4. Boccolini, G., Brazzit, A., Bonfanti, L. andAlberti, G. (2013): Using balance training to improve the performance of youth basketball players. Sport Sci Health., 9:37-42.

5. Bressel, E., Yonker, J.C., Kras J. and Heath, E.M. (2007): Comparison of static and dynamic balance in female collegiate soccer, basketball, and gymnastics athletes.J Athl Train., 42:42-46.

6. Brown, C.N. andMynark, R. (2007): Balance deficits in recreational athletes with chronic ankle instability. J Athl Train., 42:367-73.

7. Çelenk,Ç.,Arslan, H., Aktuğ, Z.B. and Şimşek, B. (2018): The comparison between static and dynamic balance performances of team and individual athletes. European Journal of Physical Education And Sport Science.,4(1):28-34.

8. Elena, S., Georgeta, N., Florentina, P., Cristiana, P., Cecilia, G. and Elena, L. (2015): Study of dynamic postural control in young adults. Science, movement and health., 15(2):515-520

9. Fernandez, W., Yard, E. and Comstock, R. (2007): Epidemiology of lower extremity injuries among U.S. high school athletes. AcadEmerg Med., 14(7): 641-645.

10. Fong, D., Hong, Y., Chan, L., Yung, P. and Chan, K. (2007): A systematic review on ankle injury and ankle sprain in sports. Sports medicine.,37(1): 73-94.

11. Gerbino, P.G., Griffin, E.D. andZurakowski, D. (2007): Comparison of standing balance between female collegiate dancers and soccer players. Gait Posture.,26(4):501-507.

12. Ghosh, S.S. andMajumde, M.S. (2012): A comparative study on agility and dynamic blance of football volleyball and hockey players. International Journal of Health, Physical Education and Computer Science in Sports.,8(1):48-50.

13. Gualtieri, D., Cattaneo, A., Sarcinella, R., Cimadoro, G. andAlberti, G. (2008): Relationship between balance capacity and jump ability in amateur soccer players of different ages. Sport Sci Health., 3:73-76.

14. Gürkan, A.C. (2016): Comparison of Right- and Left-Leg Balance Points in Female Volleyball Players and Sedentary Controls. Anthropologist., 24(3): 746-750.

15. Horak, F.B. (1987): Clinical measurement of postural control in adults. PhysTher., 67:1881-1885.

16. Hrysomallis, C. (2011): Balance ability and athletic performance. Sports medicine., 41(3): 221-32.

17. Hrysomallis, C., McLaughlin, P. and Goodman, C. (2006): Relationship between static and dynamic balance tests among elite Australian football players. J Sci Med Sport.,9:288-91.

18. Jacobson, G.P., Newman, C.W. and Kartush, J.M. (1997): Handbook of balance function testing. San Diego (CA): Singular Publishing Group., pp. 261-79.

19. Khasawneh, A. (2015): Anthropometric measurements and their relation to static and dynamic balance among junior tennis players. Journal of Sport Science.,8(11):87-91.

20. Khuman, P.R., Kamlesh, T. and Surbala, L.,(2014): Comparison of static and dynamic balance among collegiate cricket, soccer and volleyball male players, International Journal of Health \& Allied Sciences., 3(1):9-13.

21. Marchetti, P.H., Hartigan, E.H. and Duarte, M. (2012): Comparison of the postural control performance of collegiate basketball players and nonathletes. Athletic Training \& Sports Health Care.,4(6):251-256.

22. Matsuda, S., Demura, S. and Uchiyama, M. (2008): Centre of pressure sway characteristics during static onelegged stance of athletes from different sports. J Sports Sci., 26:775-779.

23. Melam, G.R., Alhusaini, A.A., Perumal, V., Buragadda, S. and Kaur, K. (2016)Comparison of static and dynamic balance between football and basketball players with chronic ankle instability. Saudi Journal of Sports Medicine., 16(3):199-204.

24. Michael, E. and Rogers, M.E. (2003): Balance and bands. The Journal Active Aging., pp.24-32.

25. Mondal, S., Nayek, B. and Chatterjee, K. (2016): A comparative study on strength, agility and dynamic balances between volleyball and basketball players.International Journal of Physiology, Nutrition and Physical Education., 1(2): 81-84.

26. Nashner, L.M. (1982): Adaptation of human movement to altered environments. Trends in Neuroscience.,5:351-361. 
27. Orchard, J. (2002): Is there a relationship between ground and climatic conditions and injuries in football? Sports Med., 32:419-432.

28. Pandey, A. andVenugopal, R. (2016):Comparison of dynamic balance using SEBT between athletes and nonathletes. International Journal of Physical Education, Sports and Health.,3(2): 238-240.

29. Paterno, M., Myer, G., Ford, K. and Hewett, T.(2004): Neuromuscular training improves single-limb stability in young female athletes, Journal of Orthopaedic \& Sports Physical Therapy., 34(6):305-316.

30. Paul, P. and Nagarajan. (2015): Comparison of Dynamic balance in lower Limbs among Knee Injured and Uninjured male Professional Footballers. Int. Res. J. Biological Sci., 3(5): 80-84.

31. Plisky, P.J., Rauh, M.J., Kaminski, T.W. and Underwood, F.B. (2006): Star Excursion Balance Test as a predictor of lower extremity injury in high school basketball players. J Orthop Sports PhysTher., 36:911-919.

32. Robert, J., Butler, R., Lehr, M.E., Fink, M.L., Kiesel, K.B. andPlisky, P.J. (2013): Dynamic Balance Performance and Noncontact Lower Extremity Injury in College Football Players: An Initial Study. Sports Health.,5(5):417-422.

33. Shumway-Cook, A. and Woollacott, M.H. (1995):Motor Control: Theory and Practical Applications. Baltimore, Md: Williams \& Wilkins.

34. Thorpe, J.L. andEbersole KT. (2008): Unilateral balance performance in female collegiate football athletes. J Strength Cond Res.,22:1429-1433. 